\section{Toward a Bully-free Community: The Case of Hamilton, Ontario, Canada}

\section{Tracy Vaillancourt}

B ullying, defined as repeated, intentional abuse on the part of one or more person more powerful than the victim (Olweus, 1978), is a pervasive problem that directly and chronically affects approximately $10 \%$ of school-aged children worldwide (see Smith, Morita, Junger-Tas, Olweus, Catalano, \& Slee, 1999).

Although bullying has a longstanding history in school life (see Hughes, 1857), it has only recently received significant research and public attention. Part of the reason for the lack of consideration paid to this subject has been that the stakes have not seemed high enough. That is, being victimized by one's peers has often been thought of as a rite of passage-something that many experience and endure without consequence.

The notion that children escape from bullying unscathed is not substantiated in the literature on peer abuse. Peer victimization has been shown to predict loneliness, depression, poor self-worth, poor school attendance, and lower grade point averages (Juvonen, Nishina, Graham, 2000). Being humiliated and oppressed by peers has been consistently linked to other internalizing difficulties such as anxiety (e.g., Craig, 1998), suicidal ideation (e.g., Carney, 2000; Rigby \& Slee, 1999), and post-traumatic stress disorder (e.g., Mynard, Joseph, \& Alexander, 2000), as well as, externalizing difficulties such as delinquency (e.g., Khatri, Kupersmidt, \& Patterson, 2000), and substance abuse (e.g., Nasel, Overpeck, Pilla, Ruan, Simons-Morton, \& Scheidt, 2001). Peer abuse has also been connected to poor general health and psychosomatic complaints (e.g., Slee, 1995).

More dramatically, bullying has been directly implicated in several high profile youth suicides in Canada (e.g., 14 year-old Dawn Marie Wesley of Mission, British Columbia, 14 year-old Hamed Nastoh of Surrey, British Columbia, and 15 year-old Mark Bonokoski of Brampton, Ontario) and worldwide (see Marr \& Field, 2001). These untimely deaths have certainly served as a belated wake-up call to scholars, educators, parents, and students to address this longstanding problem.

Accordingly, prevention and intervention programs have currently been undertaken by many schools in an effort to reduce the burden of suffering endured by the victims of bullying (see Rigby, 2002). Unfortunately however, most of the anti-bullying programs implemented (and studied) have yielded only modest, short-term reductions in bullying, with the bulk of these successes occurring in programs aimed at the early years (i.e., preschool and primary), and where there was considerable "buy-in" by school staff (i.e., strong involvement and commitment in the program) (see Rigby, 2002). These modest findings are in sharp contrast to those obtained in the 1983 anti-bullying campaign that took place in Norway, which boasts a $50 \%$ reduc- tion in bullying in the Bergen region one and two years after the inception of the national program (Olweus, 1991, 1993; Roland, 1993).

It is interesting that to date; none of the published anti-bullying intervention programs have matched the success of the Norwegian initiative. Perhaps the reason for these differences has to do with the level of involvement by the broader community, that is, the community beyond what Bronfenbrenner (1979) would term the microsystem (i.e., the immediate social setting that influences the developing person).

Certainly, the Norwegian campaign differs from other schoolbased initiatives in that it extended well beyond the level of the individual and the school. For example, the Norwegian initiative was initiated by the Ministry of Education and not by a few local schools; it was also launched as a nationwide campaign that was "heavily featured in local and national mass media in Norway" both before and after the program was instigated (Roland, 2000, p. 137). For these reasons, the Norwegian program became a national crusade, which likely reinforced their efforts through the consistency of messaging that extended beyond the microsystem into the larger community.

This is not to say however, that the Norwegian program was a resounding success. In fact, the promising results of the program were primarily noted in areas in which support was given to schools that exceeded the national standard (i.e., sending schools the package of materials without follow-up). For example, in the successful Bergen region, school were visited by researchers who discussed the program with staff (Roland, 2000). 


\section{Toward a bully-free community}

Considering the above review, it appears that, in order to successfully reduce bullying, there likely needs to be at a minimum, support and commitment by the school staff and by the larger community. Using the African proverb "It takes a village to raise a child", the City of Hamilton, Ontario, Canada has currently undertaken a community-wide initiative to reduce bullying among its youth. Toward this goal, over 30 youth-serving agencies (Community Roundtable for the Prevention of Bullying) have come together with the shared vision of creating a bully-free community. Fortunately, unlike the Norwegian campaign, this community-wide initiative was not prompted by the suicides of its youth in response to peer-harassment, but rather, it was prompted by a private donation by two concerned citizens which served as a catalyst in uniting the youth serving agencies of this community under the initial leadership of the Hamilton Community Foundation.

Although Hamilton's movement began under more positive circumstances than the Norwegian campaign, the key components are very similar-awareness and involvement. An example of a recent awareness campaign took place on October 30th, 2003 in which over 11, 000 students in grades 6, 7, and 8 from Hamilton and surrounding communities were brought together for an anti-bullying seminar.

Using a varsity basketball game as a vehicle for dissemination, students began their day by watching a play called The Diary (commissioned by the Community Child Abuse Council of Canada), which deals with the escalating abuse of a young adolescent female. Next, in smaller groups, trained McMaster Uni- versity and Mohawk College students moderated a discussion with students concerning what could be done at their school to reduce bullying. The day ended with a varsity basketball game and a take-home package for teachers to follow-up with discussions concerning bullying.

While this anti-bullying event does not represent the panacea of bullying, it does represent a community's attempt to deliver a message regarding the negative effects bullying has on victims (awareness) and to begin to morally engage the youths of its community (involvement). Certainly, in order to effectively and abidingly reduce bullying, a cultural shift needs to take place in which positive beliefs about bullying are challenged well beyond schools walls. The Community Roundtable for the Prevention of Bullying in Hamilton believes that such a shift can take place through:

1. a shared vision,

2. consistent messaging,

3. sustainability of efforts (i.e., long-term commitment), and

4. best-practice approaches that are developmentally appropriate.

There is also appreciation that Hamilton's efforts need to be carefully evaluated and documented so that knowledge can be transferred to other communities.

While there are a plethora of promising anti-bullying programs currently in schools across the world, only a very few have been empirically examined (see Rigby, 2000). The lack of attention to this part of the process is problematic, in that decisions about which program to adopt for implementation are often based on little, if any information, about efficacy.
Although Hamilton is just at the beginning of its "cultural-shift", there is great momentum and terrific "buy-in" from the youth-serving community partners.

This enthusiasm stems from the growing recognition within the community of Hamilton that bullying is not a school problem; it is a community problem that is best dealt with using a communitybased effort that enlists the aid of all citizens. Indeed, "[s]chools do not exist in isolation, but are inextricably bound to their communities. As a result, much of the work undertaken in schools is negated as a result of out-of-school attitudes shown by older peers, "gangs", parents, and the community at large. Where patterns of behaviour are in conflict with the values of the school, but are condoned with the community, there is little hope of securing changed attitudes within schools." (Glover, Gough, Johnson, \& Cartwright, 2000).

\section{References}

Bronfenbrenner, U. (1979). The ecology of human development: Experiments by nature and design. Harvard University Press, Cambridge, Massachusetts.

Carney, J.V. (2000). Bullied to death: Perceptions of peer abuse and suicidal behaviour during adolescence. School Psychology International, 21, 213-223.

Craig, W.M. (1998). The relationship among bullying, victimization, depression, anxiety, and aggression in elementary school children. Personality and Individual Differences, 24, 123-130.

Glover, D., Gough, G., Johnson, M., \& Cartwright, N. (2000). Bullying in 25 secondary schools: Incidence, impact and intervention. Educational Research, 42, 141-156.

Hughes, T. (1857). Tom Brown's school days (2nd edition). Cambridge MacMillian.

Juvonen, J., Nishina, A., \& Graham, S. (2000). Peer harassment, psychological adjustment, and school functioning in early adolescence. Journal of Educational Psychology, 92, 349-359.

Khatri, P., Kupersmidt, J.B., \& Patterson, C. (2000). Aggression and peer victimization as predictors of self-reported 
behavioural and emotional adjustment. Aggressive Behavior, 26, 345-358.

Marr, N. \& Field, T. (2001). Bullycide: Death at playtime. Wessex Press, Wantage Oxfordshire. Mynard, H., Joseph, S., and Alexander, J. (2000). Peer-victimisation and posttraumatic stress in adolescents. Personality and Individual Differences, 29, 815-821.

Nansel, T. R., Overpeck, M., Pilla, R. S., Ruan, W. J., Simons-Morton, B., \& Scheidt, P. (2001). Bullying behaviors among US youth: prevalence and association with psychosocial adjustment. Journal of the American Medical Association (JAMA), 285, 2094-2100.

Olweus, D. (1978). Aggression in the schools: Bullies and whipping boys. Hemisphere Press: Washington, DC.

Olweus, D. (1991). Bully/victim problems among school children: basic facts and effects of a school-based intervention program. In D. J. Pepler \& K. H. Rubin (Eds.) The development and treatment of childhood aggression, Erlbaum, Hillsdale, NJ, p. 411-448.

Olweus, (1993). Bullying at school. Blackwell Publishers: Oxford and Cambridge, MA.

Rigby, K. \& Slee, P. (1999). Suicidal ideation among adolescent school children, involvement in bully-victim problems, and perceived social support. Suicide and Life-Threatening Behavior, 29, 119-130.

Rigby, K. (2002). A meta-evealuation of methods and approaches to reducing bullying in pre-schools and early primary school in Austrailia. Commonwealth Attorney-General's Department: Canberra.
Roland, E. (1993). 'Bullying; a developing tradition of research and management'. In D., P., Tattum (ed) Understanding and Managing Bullying, (pp. 15-30), Heinemann Educational: Oxford.

Roland, E. (2000). Bullying in school: Three national innovations in Norwegian schools in 15 years. Aggressive Behavior, 26(1), 135-143.

Slee, P.T. (1995). Bullying: health concerns of Australian secondary school students. International Journal of Adolescence and Youth, 5, 215-224.

Smith, P., K., Morita, J., Junger-tas, D., Olweus, D., Catalano, R. \& Slee, P., T. (1999). The nature of school bullying:a cross-national perspective, Routeledge: London.

\section{The Stay Alert... Stay Safe Bullying Quiz}

Try to choose the correct answer for each of the following questions. With this multiple-choice quiz, you can test your knowledge on how to not be a victim... or a bully.

1. Bullying is a problem that affects...
a) victims
b) bullies
c) communities
d) all of the above

2. By definition, bullies are...

a) generally aggressive toward their classmates, teacher, parents, siblings and others

b) happy children who just like to tease

c) well-liked and highly popular amongst their peers

d) caring, sensitive people

3. If you are being bullied, you should...
a) start crying
b) fight back
c) ignore the bully and walk away
d) laugh at the bully

4. Victims of bullying are generally known to...
a) deserve what they get
b) be funny looking
c) be unpopular at school
d) none of the above

5. You are in the schoolyard and a kid four inches taller and much stronger than you approaches. With his fist in the air, he screams "You pushed me in line at lunch today. What are you going to do about it? Answer quick or I'll break your face." Your immediate response should be...
a) "Leave me alone" ...then walk away.
b) Threaten to break his face too
c) Give a clever or funny response such as "Thanks, but I like my face just the way it is."
d) a or c

6. Bullies tend to pick on:
a) kids who are older and bigger than they are
b) kids who are all alone
c) kids who play together in a group
d) kids who play close to the teacher

7. The following behaviour may prevent you from becoming a victim of a bully...
a) becoming a bully yourself
b) walking tall and with confidence
c) taking up kick-boxing
d) playing by yourself at recess

8. Bullying comes in many forms. It can be...
a) physical (hitting, punching, kicking)
b) verbal (name calling, sarcasm, threats, teasing)
c) emotional (tormenting, ridiculing, or humiliating another person)
d) all of the above 